\title{
PRELIMINARY COST-EFFECTIVENESS ANALYSIS OF THE MEASURES PUT IN PLACE BY EU MEMBER STATES TO IMPLEMENT THE DIRECTIVE ON REDUCTION OF SULPHUR CONTENT IN FUELS USED BY SHIPS
}

\author{
FRANCESCO ROTOLI ${ }^{1}$, GUIDO CALCAGNO ${ }^{1}$, SERGIO ALDA $^{1}$, MERCEDES GARCIA HORRILLO $^{1}$, \\ STEFANO RICCI ${ }^{2} \&$ LUCA RIZZETTO ${ }^{2}$ \\ ${ }^{1}$ EMSA - European Maritime Safety Agency, Portugal \\ ${ }^{2}$ Department of Civil Environmental and Building Engineering, University of Rome "La Sapienza", Italy
}

\begin{abstract}
For Europe, maritime transport has always been a catalyst for economic development and prosperity throughout its history. The European Union (EU) has adopted one of the most stringent maritime safety and marine environment legislation in the world. Its aim is to ensure a high level of safety, prevention of pollution and a level playing field, where all shipping operators, who follow good practices, are not put at a commercial disadvantage compared to those taking shortcuts in ship safety or pollution prevention. As part of this effort, the European Commission ensures that EU Member States correctly implement the EU maritime acquis, to lower the risk of serious maritime accidents and to minimise the impact of maritime transport on human health and the environment. In this context, the EU's European Maritime Safety Agency (EMSA) provides technical support to the European Commission and EU Member States in developing a uniform and consistent implementation of EU legislation on maritime safety, prevention of pollution from ships and security. A useful technique to assess and improve the implementation and enforcement of the EU maritime acquis is a cost-effectiveness analysis of all the related implementation measures put in place by Member States. This paper describes the background, the framework and preliminary results of a cost-effectiveness analysis (CEA) of Member States' measures to implement Directive (EU) 2016/802, also referred to as the Sulphur Directive. The Sulphur Directive aims to reduce harmful health effects and environmental damage caused by sulphur dioxide $\left(\mathrm{SO}_{2}\right)$ emissions resulting from the combustion of some liquid fuels, including marine fuels. The outcome of this CEA may be used by the EU institutions and Member States to share relevant best practice and trigger discussion on common issues, possible ways forward and dissemination of good working practices for a more effective and efficient implementation of the Sulphur Directive at the European and national levels.

Keywords: cost-effectiveness analysis, sulphur pollution, European Union legislation, pollution from ships, air quality.
\end{abstract}

\section{INTRODUCTION}

For Europe, maritime transport has been a catalyst for economic development and prosperity throughout its history. Maritime transport enables trade and contacts between all European and world nations. It ensures the security of supply of energy, food and commodities and provides the main vehicle for European imports and exports to the rest of the world.

One of the European Commission's objectives is to protect Europe with very strict safety rules preventing sub-standard shipping, reducing the risk of serious maritime accidents and minimising the health and environmental impact of maritime transport. The European Commission's strategic goals and recommendations for the EU had been set out in 2009 in the Maritime Transport Policy until 2018 [1].

Improving the environmental record of maritime transport was among the prime aims of the 2009 Communication which invited the European Commission, the Member States and 
the European maritime industry to work together towards the long-term objective of "zero-waste, zero emission" maritime transport. The European Commission communication on Clean Air for All (COM (2018) 330 final) [2] further highlighted the need to urgently act with measures to reduce air pollution, including from the transport sector. In its report to the European Parliament and the Council, the European Commission already provided an overview of concrete actions addressing maritime transport on the implementation of and compliance with the sulphur standards for marine fuels set out in the Sulphur Directive (COM/2018/188 final) [3].

Maritime transport is widely recognised as the most environmentally sustainable and energy efficient way of moving large quantities of cargo. Even so, the volume of shipping activity is so large that it produces a substantial amount of harmful emissions. The need for cleaner shipping has thus come into focus in relation to both emissions having a global impact, namely greenhouse gas (GHG) forcing climate change, and emissions of air pollutants particularly harmful at regional level and notably close to coastal areas and port cities (for example, sulphur and nitrogen-oxides, and particulate matter).

Sulphur dioxide, emitted when fuels containing sulphur are combusted, is a pollutant that contributes to acid deposition, which, in turn, can lead to potential changes in soil and water quality and may have adverse impacts on human health by penetrating deeply into sensitive parts of the lungs and cause respiratory system diseases.

Global shipping mostly uses heavy fuel oil with high sulphur content of up to $3.50 \%$. New sulphur emission limits were globally adopted at IMO in 2008 in MARPOL Annex VI and incorporated into EU law in 2012 (Directive 2012/33/EU), effectively lowering the global sulphur limit down to $0.50 \%$ as of 2020 . Since 1 January 2015, also stricter sulphur limits for marine fuel in Sulphur Emissions Controlled Areas (SOx-ECAs) apply $(0.10 \%)$. In addition, a $0.10 \%$ maximum sulphur requirement for fuels used by ships at berth in EU ports was introduced from 1 January 2010. Furthermore, passenger ships operating on regular services to or from any EU port shall not use marine fuels if their sulphur content exceeds $1.50 \%$ in sea areas outside the SECAs until 2020 when the new maximum $0.50 \%$ sulphur limit will apply. In order to comply with these new limits, operators may use low sulphur fuel, install on-board filters (scrubbers) or adopt alternative fuel technologies.

In the EU, Directive (EU) 2016/802, known as the Sulphur Directive [4], regulates SOx emissions from ships, while Commission Implementing Decision (EU) 2015/253 [5] lays down the rules concerning the sampling and reporting as regards the sulphur content of marine fuels. The Sulphur Directive's principal aim is to reduce harmful health effects and environmental damage caused by sulphur dioxide emissions resulting from the combustion of certain types of liquid fuels. It establishes limits on the maximum sulphur content of gas oils, heavy fuel oil in land-based applications as well as marine fuels.

In its report to the European Parliament and the Council, the European Commission provided a very comprehensive overview of the implementation and compliance with the sulphur standards for marine fuels set out in the Sulphur Directive in particular during years 2015-2017 (COM/2018/188 final).

Within this context, the European Maritime Safety Agency (EMSA) has been providing technical assistance to the European Commission on the preparation of amendments to the Sulphur Directive, development of related Commission Decisions or reviewing of the annual reports submitted by Member States on compliance with the sulphur standards of the Directive. Based on an agreed action plan, the Agency was tasked by the Commission to support the Member States with the implementation of the directive through the development of inspection guidance [6] and the organization of training seminars for sulphur inspectors. Furthermore, the Agency provides technical assistance to the Commission and the Member 
States during meetings of the so-called Sulphur Committee convened under the auspices of the European Commission.

EMSA also facilitates a harmonized reporting of the implementation and enforcement of the Sulphur Directive by the Member States. To this end, the Agency developed the dedicated European Union information system known as THETIS-EU for the recording of the outcome of the verifications on board, as well as for exchange of information and alerts, which has been available since 1 January 2015. EMSA acts as technical secretariat of the European Sustainable Shipping Forum (ESSF) which was conceived in response to the challenges created by the Sulphur Directive. In particular, the Agency was deeply involved in the forum's Implementation Sub-Group, which had a central role in carrying out the most urgent tasks facilitating a timely and cost-effective implementation and enforcement of the Sulphur Directive. Furthermore, EMSA monitors developments at international level related to $\mathrm{SOx}$ emissions from shipping through its participation in various forums and conferences. On behalf of the European Commission, the Agency closely follows progress at IMO on various related issues like working groups on air emissions, introduction of a global cap and its consistent implementation globally and correspondence groups on fuel oil availability and quality.

The European Commission also mandated EMSA to carry out a cycle of visits to Member States to monitor the effective implementation of the Directive and relevant implementing legislation. EMSA visits typically take several days during which the national legislation and procedures are discussed in detail with the different competent authorities (e.g. Ministries, Coast Guard, as well as local authorities such as port authorities). The cycle of visits started in October 2016 and is expected to be completed in 2021. Initial reactions from the Member States underline the thoroughness of the visits and confirm how EMSA's findings increase mutual understanding and serve as catalyst for national dialogue and for follow-up actions to ensure the effectiveness of national implementation measures. Once all Member States have been visited, EMSA will provide the Commission with a horizontal analysis report containing horizontal findings and general conclusions on the effectiveness and cost-efficiency of the measures in place to implement the directive.

\section{COST-EFFECTIVENESS ANALYSIS (CEA)}

CEA is a technique that relates the costs of a project to the accomplishment of its planned achievements. It is particularly appropriate for evaluating the effectiveness of some measures or actions and relating them to the resources put in place to carry them out [7].

The terms effectiveness and efficiency are explicitly mentioned by the EMSA Founding Regulation in Article 3.5, which provides that "where appropriate, and in any case when a cycle of visits or inspections is concluded, the Agency shall analyse reports from that cycle with a view to identifying horizontal findings and general conclusions on the effectiveness and cost-efficiency of the measures in place. The Agency shall present this analysis to the Commission for further discussion with Member States in order to draw any relevant lessons and facilitate the dissemination of good working practices".

In this regard, EMSA has developed a cost-efficiency assessment methodology for such type of analysis, which, taking the general CEA concepts and practices currently used in many fields, adapts them to the specific EU legislative framework and its Member States' implementing efforts.

In this context. effectiveness refers to the extent to which the different objectives and goals of a piece of legislation are met. The more goals are achieved, the higher the effectiveness. On the other hand, efficiency relates to the way in which inputs (resources) are converted 
into outputs (results). An assessment of cost-efficiency would attempt to achieve the maximum number of outputs with the minimum possible costs (inputs).

In this analysis the costs incurred by the main stakeholder affected by the legislation mandate, i.e. Member State administrations, were the only ones taken into account, as opposed to a societal approach which would also take into account the costs incurred by all potentially affected stakeholders (citizens, industries, environment, etc.). Furthermore, the model used focused particularly on the associated direct costs (partial cost-effectiveness analysis) of the elements directly associated with the requirements laid down in the EU legislation under analysis, as implemented and enforced by the Member States (i.e. without considering the indirect costs which would also feature in a full cost-effectiveness analysis). The model also assumes a uniform level of quality and diligence among Member States when generating the same output indicators (i.e. inspection of a ship or provision of national officer training) and therefore does not focus on the potential deviation or deficiencies as regards the quality of each of the outputs produced.

The real added value from this analysis should focus on the ways in which the different Member States are reaching those safety and environmental goals in terms of costs, so that comparative analysis and lessons can be drawn therefrom. This in turn allows for additional assessment in relation to possible ways to reduce the associated costs when producing the required output (efficiency). It should be noted that the cost-effectiveness analysis does not intend to evaluate the Directive itself but the way in which the Member States have adapted their own national framework scenarios in order to accommodate the Directive requirements. Nevertheless, the CEA should also constitute useful feedback to the European Commission and Member States that may facilitate not only the implementation and enforcement but also future developments of European policy and legislation.

\section{CEA APPLIED TO THE SULPHUR DIRECTIVE}

The CEA, being also part of the Horizontal Analysis of the visit cycle, provides an overall comparative analysis of the costs incurred by Member States (with focus on human resources and investments in equipment) when complying with the requirements of the Sulphur Directive as part of the overall relevant cost-efficiency assessment. It is not intended to verify any regulatory compliance of each Member State.

In particular, the scope and development of this preliminary study has been defined by its intermediate nature (being at the date of this paper approximately half way in the cycle of visits to Member States) and by the large amount of information to be screened, processed and analysed in order to generate a meaningful exercise. This first analysis will develop into an even more comprehensive and meaningful version as it is consolidated by additional responses and data collated over the course of the cycle of EMSA visits to Member States during the Sulphur Directive visit cycle. Despite its rather provisional nature however, it already provides meaningful indications and reflections on the cost effectiveness elements of the implementation of this Directive.

In order to carry out this exercise, EMSA has preliminarily carried out relevant data collection and pre-assessment analysis of the available information from both THETIS-EU and previous EMSA reports. This information was complemented through dedicated questionnaires that were sent to all EU and EFTA Member States. Some of the questions required just a confirmation of the data provided during the EMSA visits and/or from the THETIS-EU database. Other questions required additional information. The majority of Member States (28 out of 30, including landlocked ones) replied to the questionnaires, providing valuable information, processed in this preliminary CEA. 
It should be noted that this CEA was exclusively based on the requirements of the Directive. As said above, effectiveness means the ratio between the actually generated effects (the outputs) and the expected effects (goals expressed through relevant requirements). It should be noted that, at implementation and enforcement level, the effects generated are calculated in the form of outputs (e.g. number of inspections and/or samples carried out, number of human resources, etc.), which are the units of effectiveness produced when meeting the requirements. Compliance with these requirements is supposed to help to fulfil one or more Directive objectives (the expected effect). The ratio between the key output indicators associated with one or more relevant requirements (effectiveness) and the costs incurred by each Member State (the input used by the Member State) to comply with each of those requirements, provided an indication of efficiency of the measure in place and formed the cost-effectiveness balance.

\section{EXAMPLES OF THE MAIN OUTCOMES OF THE PRELIMINARY CEA OF DIRECTIVE (EU) 2016/802}

This section provides some of the main outcomes of the preliminary CEA of Directive (EU) 2016/802. The graphs and the results featuring hereunder refer to data for 2016, and are presented in an anonymised way, considering that the main objective of the CEA is to identify difficulties, best practices and ways forward in relation to the measures put in place to implement and comply with the Directive requirements. The analysis looks at the EU as a whole, focusing on weak and strong points in the implementation of the Sulphur Directive, without any state-specific focus on regulatory compliance assessment. It should rather foster a cooperative discussion and sharing of information on common issues, feasible and implemented good practices and possible actions to achieve a more effective and efficient implementation of the Directive. The Sulphur Directive appears as a human resource intensive directive, where the most significant item of cost depends upon the need for trained and qualified personnel, mainly sulphur inspectors. National officers carry out inspections and, to do so, they should receive the suitable training and be located in relevant ports taking into consideration, among other things, major maritime traffic concentration spots.

\subsection{Annual full-time equivalent sulphur inspectors versus annual travel time}

Fig. 1 displays the relationship between the number of annual full-time equivalent sulphur inspectors per Member State and the maximum annual travel time per inspector (each bubble represents a Member State and its size is proportional to the number of its port districts).

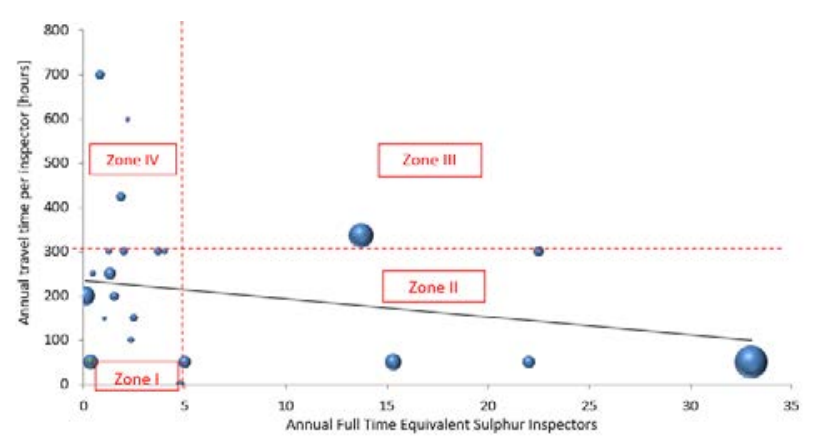

Figure 1: Annual full-time equivalent sulphur inspectors versus the maximum annual travel time per inspector. 
In general, it is noted that the Member States with five or more full-time equivalent inspectors report relatively lower travel time for their inspectors (in the range of $0 \div 50$ hours/year per inspector), except for one Member State, which, however, has many port districts and the highest number of ship calls (in the reference year 2016) among Member States. Three Member States reported inspector's annual travel time significantly higher than the others did (more than 350 hours per year, i.e. around 1.5-2 hours per day). At the same time, they also reported a smaller number of dedicated sulphur inspectors in comparison to other Member States. Two Member States receive a high number of ship calls, thus the respective sulphur inspectors may experience high workload and commuting time in relation to the different, sometimes distant, port districts.

From the analysis above it can be observed that there are two alternative strategies followed by Member States in relation to the number of dedicated sulphur inspectors and the annual travelling time, also depending on the number of port districts:

- Member States allocating staff for sulphur inspections in each port or port district, may incur higher employee costs but such personnel may be dedicated also to other tasks, optimising the available human resources.

- Member States with fewer sulphur inspectors may save personnel costs but incur increasing travelling costs and time spent (especially in case of many ports/port districts) which results in less availability of the inspectors to accomplish other different tasks.

Each Member State should carefully assess which arrangements best fit its characteristics (number and distance of ports and port districts, annual ship calls, etc.) in order to manage, as efficiently as possible the available and often limited resources.

\subsection{Non-compliances raised during inspections with sampling}

The objective of an on-board inspection is to verify that a ship is compliant with the requirements of the Directive. This enforcement effort ultimately aims at eliminating the number of potential non-compliant ships. Member States have been asked to indicate the number of non-compliances raised during inspections (including the analysis of sulphur content in fuel samples). These two variables may be considered significant units of output and their ratio a possible effectiveness ratio. Based on Member States' replies, the relationship between the number of inspections with sampling and the number of related non-compliances (Fig. 2) shows cases of several non-compliances either cases of relatively low rates of non-compliance.

It is interesting to note a possible effectiveness correlation between the higher ratios of non-compliances accomplished by some Member States and the fact that they use remote sensing technologies and quick scan analysers to support their inspection efforts. Green bubbles represent these Member States in Fig. 2. Conversely, it appears that those Member States, which do not in principle employ any such risk-based targeting mechanism (denoted by blue bubbles), seem to have raised fewer non-compliances, which may suggest less effectiveness in detecting them.

Establishing appropriate risk-based targeting mechanisms and sampling procedures are key actions to increase the cost-effectiveness of the verification process. This would increase the probability of detecting non-compliances, also ensuring correct and non-biased results of the verifications. In particular, remote sensing and quick scan technologies, despite the initial investment cost imposed on Member States, may help in better targeting vessels to inspect and making more effective and efficient the whole fuel sample collection activity. 


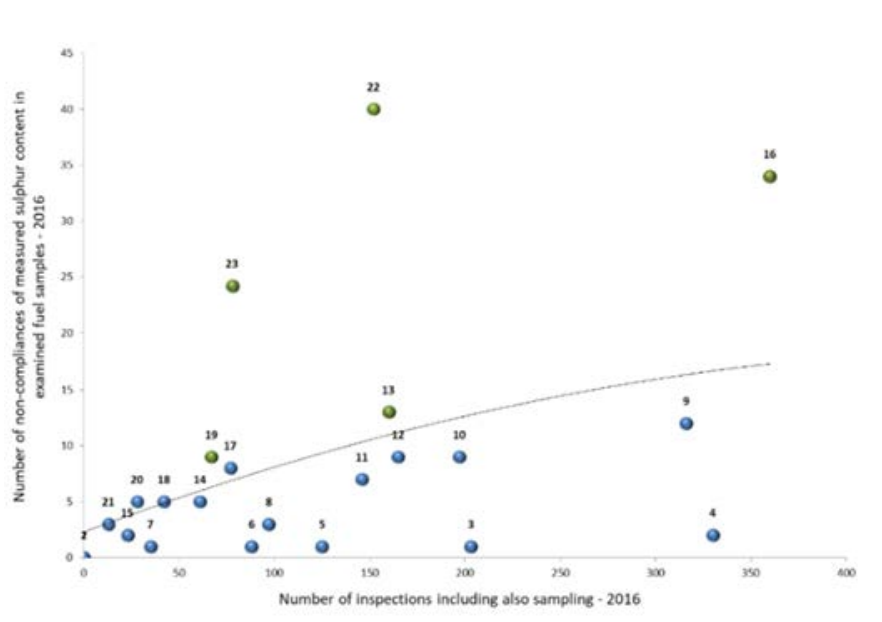

(a)

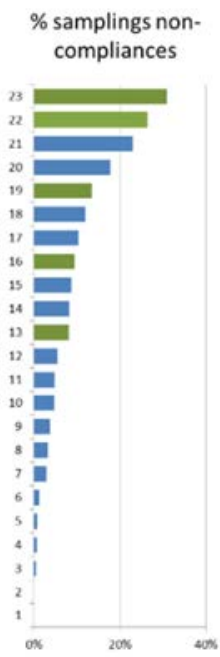

(b)

Figure 2: (a) Number of non-compliances versus number of inspections with samplings (2016); (b) Percentage of samplings which ended up in non-compliance.

\subsection{Remote sensing and quick scan technologies}

The remote sensing measurement of the sulphur content of marine fuels appears to be a cost-effective option to provide initial indications as to whether a ship uses compliant fuel. Member States that have placed sniffers on appropriate fixed or mobile platforms use them primarily not as proof of non-compliant fuel used on board, but rather as a tool to better target specific ships for further inspections on board, which may include fuel sampling and subsequent sample laboratory analysis. On the other hand, experience by some Member States highlighted that, even if remote sensing is considered a useful tool, there are still conditions which may bias the measurement, possibly causing false positives (alerts for vessels which are actually using fuel with sulphur content below the limit) or vice versa. For instance, there are conditions typical of port areas, where the engines in the manoeuvring phase and under low speed may cause variation in the $\mathrm{CO}_{2}$ and sulphur ratio which may affect the measurement taken from these devices. Other cases may happen in areas where wind and general meteorological conditions may distort the measurement of SOx concentration, making it difficult to trace back the measurement to a specific pollutant ship.

As regards cost issues, Member States using remote sensing indicated an average cost of around $50 €$ per measurement through fixed sniffers (for instance placed under bridges or specific locations close to ships' passages) and a cost of around $500 €$ for each remote measurement taken from sniffers placed on board aircraft. A few Member States have started using drones and boats equipped with sniffers as possible cheaper remote sensing platforms.

Similarly, quick scan analysers are used to provide an initial on-board estimation of fuel quality. If necessary, when the quick scan measurement yields sulphur content close to or above the limits, the remaining portion of the sample is taken to the laboratory for more precise and legally certified analysis. Based on the results of the laboratory, some preventive action related to the sanctions and penalties procedures may be initiated before the ship leaves the port. 
Based on Member States' replies, the cost of a portable sulphur content analyser ranges between 30,000 $€$ and 40,000 $€$ (with quite low maintenance costs). Member States that have started to use them report a satisfactory experience and these devices are considered a good "value-for-money" option considering the initial small investment and the operational benefits derived.

\subsection{Shipping costs per sample versus average delivery time}

Member States also provided their best estimation for the shipping costs per sample and the average delivery time (sample to laboratories and analysis' result back).

The bubbles in Fig. 3 represent the ten Member States, which provided a reply to this question in the $[\mathrm{x}-\mathrm{y}]$ plane, shipping costs per sample versus average delivery time.

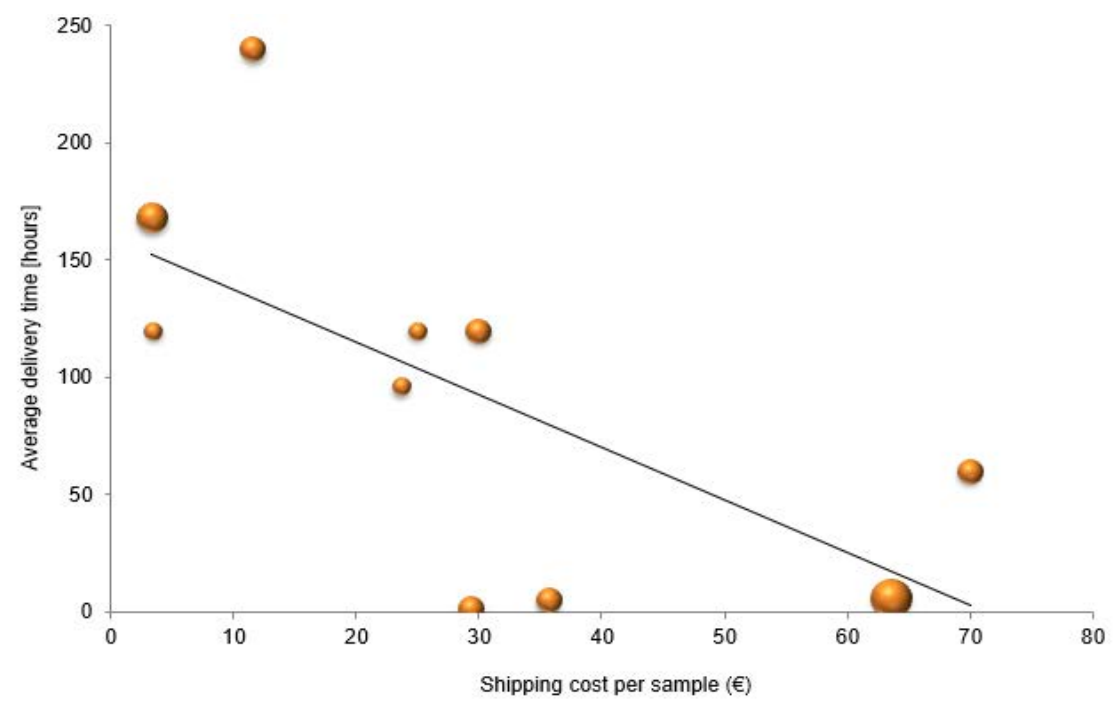

Figure 3: Shipping cost per sample versus average delivery time (the size of the bubbles is proportional to the number of port districts).

As reasonably, shorter delivery-time corresponds to higher shipping cost per sample. It seems that Member States with longer sample delivery chains and related times, may organise the transportation arrangements more efficiently, for instance by collecting more samples from different ships and sending them to the laboratory grouped in bigger sample stocks. This arrangement may consequently imply lower unitary shipping cost. However, this arrangement may not be effective for having results early in time for possible further prosecution in case of non-compliance.

It is interesting to note that usually laboratory tests on fuel samples take only a few hours to be conducted. Often a great part of the time required from the sampling to receipt of the results is related to transportation and logistics. For example, during the EMSA visits to some Member States it was noted that the samples were first sent to a centralised collecting office and then forwarded to the laboratories concerned. This process inevitably took a few days to be carried out. From Member States' experience it appears that the overall time to analyse fuel samples is much shorter in those Member States where the fuel samples are directly 
delivered to the laboratories without intermediate steps (less storage and shunting time). Long delivery times (from the moment samples are taken on board until the analysis results are available) may not be fully effective from an enforcement point of view, having an impact on the effectiveness of the penalty and sanction system. This may be the case when the vessel leaves the port before the analysis results are received by the competent authority, making it difficult to effectively raise non-compliances or to issue sanctions.

From a cost-efficiency point of view, Member States appointing more laboratories for testing sulphur content of marine fuels may reduce samples' delivery time. Feedback from Member States indicates that, in some of them it was not easy to find and appoint several accredited laboratories, mainly due to possible lack of such facilities or for cost control reasons (e.g. transport, number of samples per lab etc.). Each Member State should carefully evaluate which laboratory arrangements fit best its characteristics (number and distance of ports and port districts, annual ship calls, annual obligation for inspections with sampling, etc.) to manage, as efficiently as possible, the laboratories and the resources available in its territory.

\subsection{Sanction and penalty system}

Another important element of this CEA was to assess the extent to which Member States ensure the enforcement of the Sulphur Directive through establishing and using an effective sanction and penalty system for breaches to the Directive requirements. The Directive defines the effectiveness criteria for a penalty system, stating in Article 18 that "Member States shall determine the penalties applicable to breaches of the national provisions adopted pursuant to this Directive. The penalties determined shall be effective, proportionate and dissuasive and may include fines calculated in such a way as to ensure that they at least deprive those responsible of the economic benefits derived from the infringement [...] fines gradually increase for repeated infringements".

Based on the Member States' replies to the CEA questionnaire, 320 infringements arose in the EU in the reference year 2016. Of these, 226 infringements have been accepted by the relevant operator.

Several observations can be drawn in terms of the overall effectiveness and efficiency of the penalty systems concerned:

- In some cases, the Member State was not able, for practical reasons, to notify the detected infringement to the relevant operator; in fact, it may happen that the vessel leaves the port before potential non-compliances are verified (upon reception of laboratory analysis), making impossible to directly issue a fine;

- In some other cases, even if the infringement is notified to the relevant operator, the money collection can take a long time: either because the vessel has left the port (with a possible fine to be charged at the following call in the same port or at least in the same Member State) and/or because the infringements (and the related administrative or criminal sanctions) need to be handled by a court.

- The number of detected infringements appears to be quite low across Europe (as shown in Fig. 4).

- The total amount of money collected from fines differs between Member States, showing different average fines imposed (Fig. 4). This may be due to different average degree of seriousness of non-compliances established in the Member States or to different amounts imposed by the sanctions system in place for the same type of infringement. 


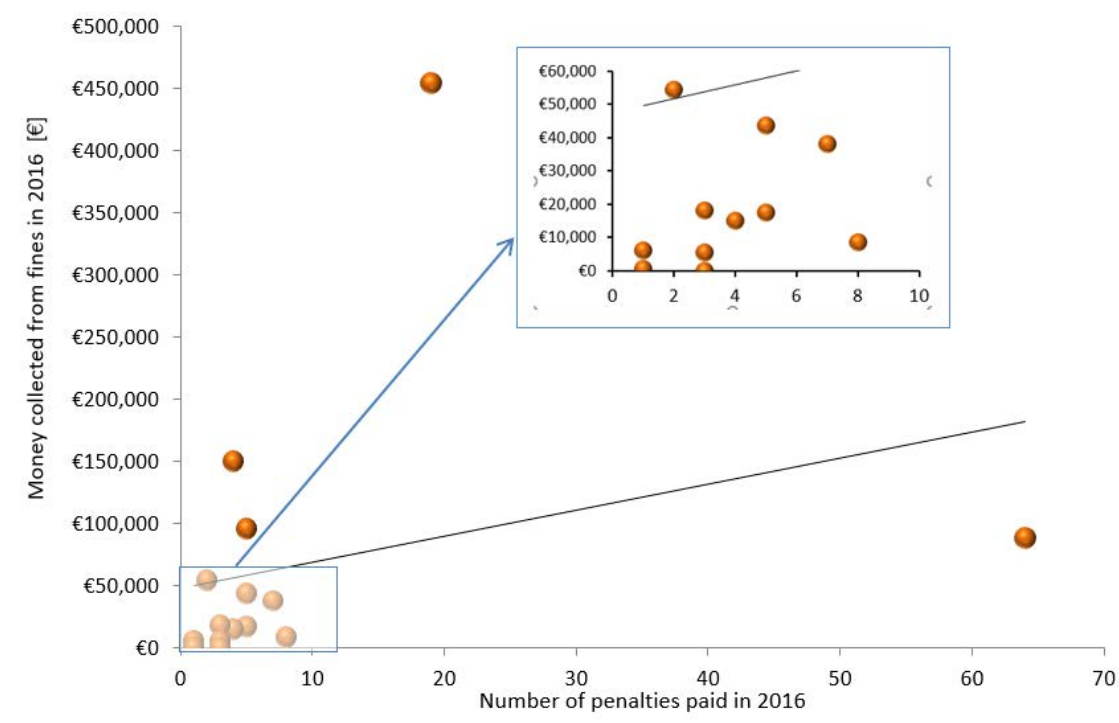

Figure 4: Number of infringements where a penalty was established and paid, versus the annual amount of money collected through the fines.

Within this context, and without prejudice to the right of each Member State to organise and manage its sanction and penalty system as deemed more appropriate, the information gathered through the EMSA visits, the annual reports submitted by Member States and the CEA questionnaire suggests the following CEA considerations:

- Penalty and sanctions systems based on judicial procedures seem to be in general less effective than systems in which fines can be issued directly by the enforcing authority by way of an administrative procedure. Judicial actions often take a very long time, bearing also the risk that they are eventually rejected at the end of the process for procedural reasons (e.g. lack of evidence of direct responsibility, impossibility of reaching the parties involved in the judgement, impossibility of carrying out further verifications, etc.); in this context, a short time to send samples to laboratories and receive the results back, coupled with the use of quick scanner analysers, could help improve the response time to ascertain possible infringements of sulphur content limits on ships.

- Requesting a financial guarantee before the vessel leaves the port seems to be a good practice that some Member States adopted in cases of preliminary indications of breaches of the Sulphur Directive but without having the possibility to issue directly an administrative fine.

- The amount of money imposed in penalties appears to be different among Member States (Fig. 4): in some Member States the fines imposed appear to be moderate, even when they are pegged to the economic benefit that the offenders would have derived from the infringement, it may be questionable if the requisite for fines to be proportional and dissuasive is being achieved.

- A better harmonisation of national sanction systems among Member States could improve the effectiveness of an enforcement level playing field, avoiding distortions 
and the risk of undesired loopholes of more favourable treatment among Member States; in this regard, it would be useful to draft voluntary best practice guidance that may help Member States determine what sanctions are actually proportionate, effective and dissuasive: the best practice guidance could recommend sanction types and minimum amounts per type of infringement by, for instance, developing a matrix to estimate proportionate penalty amounts and the right forum for drafting and adopting such best practice guidance could be the Sulphur Committee.

\subsection{Sulphur dioxide concentration values in port and coastal areas}

The ultimate objective of the Sulphur Directive in relation to fuel used by ships is to improve air quality especially in port and coastal areas. Therefore, a cost-effectiveness analysis of the measures put in place by Member States to implement the Sulphur Directive has to take as an ultimate effectiveness indicator the change (hopefully decrease), in sulphur concentration measurements in a number of significant locations close to ports and coastal areas of the Member States.

As requested in the CEA questionnaire, Member States have reported the average values of sulphur dioxide concentration over the calendar years from 2014 until 2016 in many sampling points of their coastal and port areas. Some Member States provided very detailed data. From the data received it appears that the sulphur concentrations are very low and have been reduced from 2014 to 2016 . This provides confirmation of the positive impact of the Directive's implementation on the air quality in coastal and port areas. The improvements are even more evident considering the concentration values over the last two to three decades which show a clear positive effect of European (and international) policies (including the Sulphur Directive) on the air quality in the Member States' territories.

\section{CONCLUSION}

The paper briefly describes the background, the framework and some results of a preliminary CEA of the measures put in place by EU Member States to implement the Sulphur Directive.

The intensification of efforts outlined in the European Commission report to the European Parliament and the Council (COM/2018/188 final) has led to significantly increasing the cost-efficiency and uniformity in the application of the sulphur provisions. However, the data and outcomes stemming from this preliminary cost-effectiveness analysis still indicate differences between Member States in respect of the measures, activities and resources they put in place to comply with the Sulphur Directive. These different implementation and enforcement measures were the result of different approaches followed by the Member States and consequently implied different costs and extents of effectiveness of the activities undertaken to comply with the output required and finally to achieve the objectives of the Directive. These differences are also due to specific characteristics of each Member State (number and distance of ports and port districts, annual ship calls, personnel engaged, etc.) which should be carefully evaluated to manage as efficiently as possible the available and often limited resources.

The CEA suggests that, in some areas, different approaches may create loopholes in the EU-wide sulphur enforcement framework, while a better harmonisation of the national enforcement systems and actions among Member States could improve the effectiveness and uniformity of the enforcing regime, avoiding distortions and potentially perceived more favourable (or unfavourable) treatments among Member States.

On the other side, the cost-effectiveness exercise highlighted some good practices already in place in some Member States and/or advisable ways forward to possibly 
consolidate strengths, minimise weaknesses or problematic areas, and generally to improve the cost-effective implementation of the Sulphur Directive requirements.

The main goal of cost-effectiveness analyses carried out by EMSA is exactly to gather and provide a useful set of information which may be used by the European Commission and by Member States to share and trigger discussion on common issues, possible ways forward and good practices, for a more effective and efficient implementation of Directives addressing maritime safety and pollution (such as the Sulphur Directive) at European and national level.

\section{ACKNOWLEDGEMENTS}

We want to thank Mrs. Rosa Antidormi of the European Commission - DG Environment, for her valuable feedback, exchange of opinions and continuous support during the drafting of this paper.

Disclaimer: The views expressed in this paper are purely those of the authors and may not in any circumstances be regarded as stating an official position of the European Commission and of the European Maritime Safety Agency.

\section{REFERENCES}

[1] Communication from the Commission to the European Parliament, the Council, the European Economic and Social Committee and the Committee of the Regions, Strategic goals and recommendations for the EU's maritime transport policy until 2018. 21.1.2009 - COM (2009) 8 final, Brussels, 2009.

[2] Communication from the Commission to the European Parliament, the Council, the European Economic and Social Committee and the Committee of the Regions, A Europe that protects: Clean air for all. 17.5.2018 - COM (2018) 330 final, Brussels, 2018.

[3] European Commission, Report from the Commission to the European Parliament and the Council on implementation and compliance with the sulphur standards for marine fuels set out in Directive (EU) 2016/802 relating to a reduction in the sulphur content of certain liquid fuels. 16.4.2018, Brussels, 2018.

[4] European Parliament, Directive (EU) 2016/802 of the European Parliament and of the Council of 11 May 2016 relating to a reduction in the sulphur content of certain liquid fuels, 2016.

[5] European Parliament, Commission implementing decision (EU) 2015/253 of 16 February 2015 laying down the rules concerning the sampling and reporting under Council Directive 1999/32/EC as regards the sulphur content of marine fuels, 2015.

[6] European Maritime Safety Agency, Sulphur inspection guidance - Directive (EU) 2016/802, version May 2018.

[7] Riegg Cellini, S. \& Kee, J.E., Cost-effectiveness and cost-benefit analysis. Handbook of Practical Program Evaluation, 2015. 